\title{
Experiência escolar de jovens/alunos do ensino médio: os sentidos atribuídos à escola e aos estudos*
}

Rosemeire Reis

Universidade Federal de Alagoas

Correspondência:

Rosemeire Reis

rosemeirerreis@yahoo.com.br

* Este artigo é resultado da tese de doutorado denominada Encontros e desencontros: a relação de jovens/alunos do ensino médio com os saberes escolares, defendida em 2006, na Faculdade de Educação da Universidade de São Paulo, sob orientação da Profa. Dra. Helena Coharik Chamlian, com apoio da CAPES/ COFECUB e do CNPq.

\section{Resumo}

0 artigo apresenta resultados de uma pesquisa sobre a experiência escolar de jovens/alunos em uma escola pública de ensino médio de São Paulo. Visou-se investigar principalmente as relações desses jovens com os saberes propiciados pela instituição escolar e suas interpretações sobre o trabalho realizado para a apropriação desses saberes. Os estudantes são analisados como jovens, partindo-se do pressuposto de que levam para a escola seus saberes, suas experiências; e como alunos, devido ao fato de estarem na escola para ampliarem seus repertórios culturais a partir de um trabalho específico. A metodologia utilizada é a abordagem local, a qual, de acordo com Agnès Van Zanten, pressupõe o intercruzamento de dados procedentes de métodos próprios à abordagem etnográfica. Os instrumentos de pesquisa são os inventários de saber e as entrevistas, além de outros utilizados na pesquisa-ação em que o estudo está inserido: questionário sobre o clima escolar, discussões com grupos de jovens, observações em sala de aula. Conclui-se que os jovens/ alunos iniciam o ensino médio com uma imagem positiva da escola, mas que, apesar disso, a experiência escolar não possibilita a compreensão de aspectos específicos da apropriação dos saberes. Identificam-se, ainda, problemas em relação às regras de sociabilidade construídas na escola, sendo que os modos como vivenciam tais desafios não são homogêneos: para alguns, o dispêndio de energia ocorre porque querem ser reconhecidos pelos colegas; para outros, o maior desafio é transpor as dificuldades nos estudos. De qualquer modo, tais jovens buscam atribuir sentido para essa etapa de escolarização. As questões levantadas apontam a importância do trabalho educativo a ser viabilizado no ensino médio.

\section{Palavras-chave}

Ensino médio - Jovens/alunos - Relação com o saber - Experiência escolar - Saberes escolares. 


\section{The school experience of youngsters/pupils of secondary education: the meanings attributed to school and to studies}

Rosemeire Reis

Universidade Federal de Alagoas

Contact:

Rosemeire Reis

rosemeirerreis@yahoo.com.br

* This article is the result of the doctoral thesis called Encontros e desencontros: a relação de jovens/ alunos do ensino médio com os saberes escolares, defended in 2006 at the Faculty of Education, University of São Paulo, under the guidance of Professor. Dr. Helena Coharik Chamlian, with support from CAPES / COFECUB and CNPq.

\begin{abstract}
The article presents results from a research on the school experience of youngsters/pupils of a public secondary school in São Paulo. The aim was mainly of investigating the relations established by these youngsters with the knowledges offered by the school institution, and their interpretations of the work carried out to appropriate such knowledges. The students are analyzed as youngsters, from the standpoint that they bring into school their knowledges and experiences; and as pupils, due to the fact that they are at school to widen their cultural repertoire as a result of a specific work. The methodology employed is that of the local approach which, according to Van Zanten, presupposes the inter-crossing of data coming from methods adequate to the ethnographic approach. The instruments of the research are knowledge inventories and interviews, apart from other devices used in the action-research in which this study is immersed: a questionnaire on the school climate, discussions with groups of youngsters, observations in the classroom. The study concludes that the youngsters/pupils start secondary education with a positive image of the school, but, in spite of that, the experience at school does not allow their understanding of specific aspects of the appropriation of knowledges. Problems were also identified regarding the rules of sociability constructed at school, and that the ways in which pupils experience such challenges are not homogeneous: for some, the expenditure of energy occurs because they want to be recognized by their colleagues; for others, the biggest challenge is to overcome the difficulties in their studies. At any rate, these youngsters seek to attribute meaning to this stage of their schooling. The questions raised here point to the importance of the educative work that must be achieved in secondary education.
\end{abstract}

\section{Keywords}

Secondary education - Youngsters/pupils - Relation with knowledge - School experience - School knowledges. 
Neste texto, apresentamos a análise de uma pesquisa realizada em uma escola pública de ensino médio da cidade de São Paulo. Durante três anos, investigamos a experiência escolar de um grupo de jovens/alunos, focalizando, a partir da perspectiva desses jovens, os desafios para o diálogo entre seus saberes e aqueles propiciados pela instituição escolar, bem como suas interpretações sobre o trabalho realizado na escola para a apropriação de tais saberes.

0 estudo estava inserido em uma pesquisa-ação, mediante parceria entre um grupo de professores da escola e um grupo de pesquisadores de uma universidade pública. As análises dos dados da pesquisa-ação informam-nos de que a escola em que realizamos a pesquisa foi criada em 1948 e era uma referência entre os estabelecimentos públicos de ensino em São Paulo. Até 1992, seus candidatos deviam passar por um rigoroso exame de seleção, muito concorrido. A partir de então, com a consolidação de políticas de democratização de acesso à escola, o exame deixou de existir. Tal modificação permitiu a entrada de alunos e alunas de diferentes bairros da periferia da cidade de São Paulo, alterando de maneira significativa as características da escola, anteriormente reservada a uma reduzida elite (GALVÃO; SPOSITO, 2004).

É relevante destacar que o estabelecimento apresentava, para os alunos que nele estudavam e para suas famílias, uma imagem que remetia ao ensino de qualidade e à capacidade de cumprir o papel de preparar o jovem no sentido de propiciar um bom lugar na sociedade, um emprego valorizado e a entrada na faculdade. Tendo esse aspecto como ponto de partida, a questão que nos moveu durante a investigação foi a de compreender possíveis aproximações ou distanciamentos entre os saberes pessoais dos jovens e os saberes propiciados pela instituição escolar, em suas diferentes dimensões: sociabilidade, aspectos éticos, relação com os modos de estudar, conteúdos ensinados.

Pesquisamos, portanto, a experiência escolar desses jovens no sentido empregado por François Dubet e Danilo Martuccelli (1996). Para os autores, tal experiência é a "maneira pela qual os atores individuais ou coletivos combinam as diversas lógicas de ação que estruturam o mundo escolar" (p. 62) ${ }^{1}$. Pretendemos compreender o que a escola fabrica e, para tanto, procuramos identificar como os jovens/alunos "apropriam, compõem e articulam as diversas dimensões do sistema, com as quais eles constroem suas experiências e se constituem" (p. 67). Consideramos como parte dessas dimensões as próprias atividades propiciadas pela escola, por entender que estas contribuem para a construção de tal experiência escolar (ROCHEX, 1995)².

Compartilhamos também, juntamente com Jean-Claude Forquin (1993), a ideia de que toda educação, em particular, toda educação do tipo escolar, supõe sempre uma seleção no interior da cultura e uma reelaboração dos conteúdos destinados a serem transmitidos às novas gerações. Esses saberes são selecionados a partir do que é vislumbrado com a educação escolar em relação ao tipo de sujeito que se pretende formar. Em outras palavras, a formação proposta pela escola pressupõe uma intencionalidade, um projeto de formação dos sujeitos para determinada sociedade a partir da legitimação de certos valores, de certas capacidades cognitivas, relacionais, estéticas, reflexivas e de saber-fazer. "Isto significa dizer que a educação não transmite jamais a cultura, considerada como um patrimônio simbólico unitário e imperiosamente coerente" (FORQUIN, 1993, p. 15). Esses saberes interpretados nas diferentes áreas do conhecimento, com sua sistematização própria, produzem modos específicos de ensino, com suas concepções, com escolhas sobre o quê e como ensinar em determinado momento histórico. Consideramos também relevante a afirmação de Forquin (1993) de que a escola

é um lugar específico, onde os membros das gerações jovens são reunidos em grupos de

1- Para os referidos autores, tais lógicas articulam três funções do sistema escolar: socialização, distribuição de competências e educação (DUBET; MARTUCCELLI, 1996).

2- Os textos franceses são citados a partir de tradução livre feita pela autora. 
idade a fim de adquirir sistematicamente, segundo procedimentos e modalidades fortemente codificadas, disposições e competências que não são do mesmo tipo das que elas teriam podido adquirir ao acaso das circunstâncias da vida e em função de suas demandas espontâneas. (p. 169)

Partimos do pressuposto de que um dos grandes desafios para a instituição escolar na atualidade é propiciar o diálogo entre as experiências dos jovens estudantes e os saberes escolares. Essa concepção de diálogo aproxima-se daquela apresentada por Paulo Freire (1987): "somente o diálogo, que implica um pensar crítico, é capaz também de gerá-lo. Sem ele não há comunicação e sem esta não há verdadeira educação" (p. 83).

0 diálogo pressupõe a interação entre sujeitos em um espaço compartilhado no qual cada um expresse seus pontos de vista, reconheça a existência de outras perspectivas de análise para os mesmos assuntos e tenha predisposição para refletir sobre o que o outro pensa.

Conforme afirma Bernard Charlot (2001), um jovem em condição não favorável pode ser resistente ou passivo em relação aos saberes escolares e adotar, fora da escola, "comportamentos que apresentam certa complexidade e que supõem aprendizagens aprofundadas" (p. 17). Explica o autor que cada sujeito possui uma relação com o saber, sendo esta uma relação de sentido, de valor entre um indivíduo (ou um grupo) e os processos ou produtos do saber (CHARLOT; BAUTIER; ROCHEX, 1992; LOMÔNACO, 2003). Portanto, para Charlot (2005), “a relação com o saber é uma relação com o mundo, com os outros e consigo mesmo de um sujeito confrontado com a necessidade de aprender" (p. 45).

Para compreender essa relação de sentido, é necessário analisar como se opera a conexão entre sujeito e saber, conceber esse sujeito como um ser desejante e social, bem como tratar essa conexão a partir de uma perspectiva dialética entre sentido e eficácia, pois o sujeito apropria- -se de um saber que lhe é exterior, que lhe faz sentido, o que exige determinadas atividades (LOMÔNACO, 2003); além disso, ele reelabora tal saber internamente, de acordo com suas referências anteriores. São as atividades do sujeito que possibilitam a apropriação dos saberes.

Para Lev Vigotski (1998), a construção do psiquismo é social. Ela ocorre a partir da relação do homem com o mundo, tendo dois tipos de mediadores: os instrumentos, que regulam as ações sobre os objetos, e os signos, que organizam a ação sobre o psiquismo. A cultura humana cria o objeto e atribui-lhe sua função. Ao mesmo tempo, na medida em que esse objeto é transformado continuamente pelo homem, ele é portador de novos sentidos. A linguagem, por ser uma das formas mais elaboradas de simbolização e a principal via de interação social, realiza a mesma função do objeto em relação aos instrumentos psicológicos. Portanto, a atividade do sujeito em sua relação com os outros e com o mundo é fundamental para que ele se aproprie de um mundo que já existe antes dele e dê sentido a esse mundo. A apropriação de sistemas de signos e o domínio das condutas semióticas operam-se, de acordo com Vigotski, do exterior ao interior pela atividade realizada em cooperação com os adultos ou com os pares.

Tal como explica Jean-Yves Rochex (1995), tendo como referência os estudos de Vigotski, a apropriação da cultura mediada pela atividade dos sujeitos é um processo de dupla existência: possui uma dimensão social e histórica, bem como uma dimensão individual. As significações consolidam-se sob a forma de significações verbais, conceitos, saberes e saber fazer, aquisições das práticas sociais historicamente construidas pela humanidade. Elas, sem perderem sua natureza histórico-social e seu conteúdo objetivo, passam por um processo de apropriação de cada sujeito singular, o que pressupõe a atribuição de um sentido pessoal às significações. As signifıcações individualizam-se e subjetivizam-se. Em outras palavras, para o desenvolvimento intrapsíquico, os sujeitos necessitam realizar atividades de apropriação das 
significações culturais, as quais se revestirão dos sentidos pessoais que lhes são atribuídos.

Portanto, consideramos que a relação com o saber é construída a partir dos desafios com os quais os sujeitos se confrontam, dos encontros que tiveram com os diferentes tipos de saberes e de determinadas atividades mediadas por outros sujeitos para apropriação de tais saberes. Também na escola esse processo não é homogêneo, mas depende da qualidade dos encontros com os saberes vivenciados, da relevância das atividades propostas e dos desafios propiciados a partir da mediação de um outro. As exigências para a realização das atividades escolares podem aproximar-se ou afastar-se da relação desses jovens com o saber, dos modos como compreendem o que é aprender, de suas representações sobre o que é estudar e de seus projetos de futuro, dentre outros aspectos, implicando maiores ou menores desafios para a apropriação dos saberes escolares.

\section{Os caminhos percorridos para pesquisar como os sujeitos constroem sua experiência escolar}

Ao longo da pesquisa, deparamo-nos com estudos que reivindicam uma análise mais ampla da escolarização dos sujeitos, o que significa investigar os saberes e as experiências dos jovens não reconhecidos pela instituição escolar. Tais estudos criticam as pesquisas que analisam os sujeitos reduzindo-os à categoria de alunos (SPOSITO, 2003). Conforme assevera Juarez Dayrell (2002), por um lado, tal perspectiva restringe a educação à instituição escolar, como se esta fosse a agência exclusiva de socialização, sem reconhecer outras dimensões na construção da condição de aluno ou estudante. Por outro lado, partilhamos também do pressuposto de que "não se nasce aluno, alguém se torna aluno" (DURU-BELLATE; VAN ZANTEN apud SPOSITO, 2003). Nesse sentido, é importante levar em conta os argumentos de Elisabeth Bautier e Jean Yves Rochex, que procuram justificar a preocupação com a necessidade de ressignificar a categoria aluno. Para os autores, é necessário que os sujeitos reconheçam a especificidade de cada espaço social de que participam, para introduzirem-se nele e apreenderem sua lógica. Segundo afırmam, é imprescindível que a instituição escolar permita aos jovens compreender sua especificidade, propiciando-lhes uma confrontação com as lógicas específicas do trabalho escolar ${ }^{3}$.

Tendo tais questões como referência, optamos, no presente estudo, pela utilização do termo jovens/alunos, partindo do pressuposto de que é preciso problematizar quem são os jovens que estão chegando ao ensino médio no Brasil, identificar aspectos de sua condição juvenil, suas culturas, seus saberes, e analisar a construção desses jovens como alunos, o que pressupõe a apropriação de uma forma específica de trabalho na escola para a assimilação dos saberes escolares.

Como metodologia de pesquisa, utilizou-se a abordagem local, a qual, segundo Agnes Van Zanten (2001), pressupõe a concepção de espaço local como um site. Essa perspectiva de investigação

se apóia [sic] no intercruzamento de dados procedentes de quatro grandes tipos de métodos próprios à abordagem etnográfica: observações, fontes escritas, procedimentos de recenseamento e entrevistas. (p. 28)

Analisamos os documentos (textos produzidos pelo grupo de pesquisa; relatórios, com os resultados dos questionários, dos grupos-figura), realizamos anotações nas reuniões e nas observações em sala de aula, e recenseamos os inventários de saber e as entrevistas.

Os procedimentos e os instrumentos de pesquisa utilizados no âmbito da pesquisa-ação

$\mathbf{3}$ - Informações fornecidas por Elisabeth Bautier e Jean-Yves Rochex no seminário Systèmes éducatifs, socialisation des jeunes et processus de marginalisation, ano universitário 2003-2004, na Universidade Paris VIII, Saint-Denis, França, nos dias 23 nov. 2003, 3 e 10 dez. 2003. 
foram: em outubro de 2001, um amplo questionário sobre o clima escolar ${ }^{4}$ aplicado a 2.093 jovens (73\% do total de 3.000 alunos) pela equipe de pesquisa; em 2002, debates com dois grupos de alunos interessados em falar sobre a escola e analisar os dados obtidos no questionário (esses grupos reuniram-se durante algumas semanas, totalizando cinco encontros; em média, vinte alunos participaram desses encontros); em 2003, as observações em sala de aula de uma turma do segundo ano do ensino médio durante três meses, mediante a parceria com uma professora de arte, para acompanhar a implantação de seu projeto de intervenção.

Na pesquisa específica, os procedimentos e os instrumentos de pesquisa com os jovens/ alunos foram: em 2002, a produção dos inventários de saber (221 textos) por parte dos alunos do primeiro ano do ensino médio de sete salas de aula do período vespertino e de alunos de três salas do período noturno (50 textos), totalizando 271 inventários de saber. 0 inventário de saber é um instrumento de pesquisa elaborado e aprimorado por Charlot (1996) e por sua equipe de trabalho no qual os estudantes escrevem um texto a partir de uma insígnia previamente apresentada. 0 modelo de pergunta que Charlot (1996) utiliza é: “aprendi coisas em casa, no bairro, na escola e em outros lugares. 0 que para mim é importante em tudo isso? E agora o que espero?" (p. 51). Nos inventários, procura-se examinar o que faz sentido para os alunos naquilo que aprenderam, e as análises realizadas são tanto quantitativas, como qualitativas. Quantifica-se o número de vezes que determinados saberes são evocados e, a partir daí, estabelecem-se porcentagens. Conforme afirma Charlot (2001), trata-se de um "trabalho de identificação, de exploração, de construção de elementos e processos" (p. 23). Para a análise qualitativa, são realizadas várias leituras dos textos e identificados os temas recorrentes. Esse material foi analisado quantitativa e qualitati-

4 - Esse instrumento é uma tradução, adaptada ao contexto brasileiro, do questionário elaborado por Michael Janosz, pesquisador canadense da École de Psychoéducation da Universidade de Montreal. vamente a partir das mesmas constelações identificadas por Charlot (1999); em maio e junho de 2003, ocorreram nove entrevistas semiestruturadas com alunos que produziram os inventários de saber e que estavam no segundo ano do ensino médio. Entre outubro e novembro de 2004, realizou-se uma segunda entrevista com cinco alunas que escreveram o inventário de saber e que tinham participado da primeira entrevista em $2003^{4}$.

Esses materiais - documentos, anotações, entrevistas, inventários de saber - passaram por diferentes tentativas de interpretação. 0 cruzamento dos olhares ou o intercruzamento dos dados permitiu realizar sua triangulação (WOODS, 1987), visando identificar os aspectos recorrentes e, também, os divergentes, que serviram como base para as análises.

\section{Desvelando aspectos da vida desses jovens/alunos}

A pesquisa focalizou os estudantes dos períodos da manhã e do vespertino, embora a intenção inicial tenha sido realizar a pesquisa nos três períodos, o que não foi possível. 0 conjunto dos dados possibilitou a identificação de alguns elementos da vida dos jovens do período diurno - os novos alunos do ensino médio em moratória.

Pode-se afirmar que os pais dos jovens que investigamos utilizam a escolha de uma escola central, distante de seus bairros, como estratégia para propiciar maior oportunidade aos filhos. Tais jovens pertencem às famílias de camadas menos favorecidas da população, mas não são paupérrimos. Eles valorizam atividades artísticas e esportivas, de modo que realizam ou gostariam de realizar esse tipo de atividade; no entanto, geralmente, seus pais não têm dinheiro para custear as atividades juvenis a que seus filhos gostariam de ter acesso.

A maioria dos jovens tem uma história de escolarização anterior sem problemas, o que levou os pais a investirem na estratégia de colocar o filho ou a filha em uma escola distante, 
bem conceituada em relação às demais. Nos dados, identificam-se, em uma mesma família, escolhas diferentes dos pais para as escolas de seus filhos, a partir do argumento de que há diferentes capacidades e interesses de cada filho em relação aos estudos. Além disso, os pais desses jovens geralmente trabalham e procuram propiciar-lhes um período de moratória breve (GALVÃO; SPOSITO, 2004). Tal moratória é vivida como uma espécie de preparação para o trabalho; não se trata de uma moratória no sentido empregado por Helena Abramo (2005), como um período no qual os jovens podem viver plenamente sua juventude, afınal, eles sofrem as restrições de sua condição econômica e social. Como moram em bairros periféricos, considerados violentos por suas famílias, têm uma vida social restrita, com poucas oportunidades para participarem de grupos ou organizações culturais. Portanto, esperam ter acesso, na escola, aos saberes e a um espaço de sociabilidade para viverem suas juventudes. Esses estudantes, além de estudarem no ensino regular, realizam cursos diversos voltados à formação para uma inserção no mercado de trabalho; tem-se aí uma estratégia das famílias a fim de propiciarem minimamente aos filhos os saberes para que eles possam obter, por meio de um trabalho, as condições financeiras mínimas para garantir a continuidade dos estudos.

\section{Sociabilidade e sua relação com as práticas escolares}

Um aspecto que exerce influência indireta na relação dos jovens pesquisados com as práticas de apropriação dos saberes escolares é o desafio de sociabilidade que enfrentam nessa etapa de escolarização. São inúmeras as evidências de que, ao iniciarem a escolarização em uma instituição grande, central, com colegas de diferentes regiões, tais alunos são confrontados com outros jovens que também querem ser reconhecidos.

Os jovens formam grupos distintos integrando aqueles que compartilham de um mesmo código: gosto musical, estilo de se vestir, de falar etc. Esses agrupamentos passam por um processo constante de inclusão de uns e exclusão de outros. Tal parte da experiência escolar consome boa parcela da energia desses jovens, ocupando um grande espaço de suas preocupações, em detrimento do investimento que seria necessário para a apreensão dos saberes escolares. Eles estão muito envolvidos com a necessidade de serem aceitos em determinado grupo, ou com o sofrimento causado em razão do sentimento de exclusão.

Segundo Abramo (2005), os jovens apresentam a tendência de formar grupos espontâneos de pares, os quais se tornam importantes para a geração de símbolos de identificação e laços de solidariedade. Esses grupos de pares fazem parte de um processo de independência e diferenciação em relação à família de origem, numa busca por autonomia e elaboração de uma identidade própria. Em tal contexto, as amizades tornamse extremamente necessárias. Os jovens entrevistados apresentam também o desejo de vivenciar sua condição juvenil. Por exemplo, um deles afirma: "juventude é vida, somos mais, somos menos, somos apenas iguais a vocês humanos" (Eduardo).

Identificam-se, nos debates com os jovens em grupo, suas formas específicas de se relacionarem no cotidiano escolar, com a classificação dos grupos e os saberes que possuem sobre os códigos criados e partilhados no espaço escolar. Na escola, configuramse grupos diferenciados, denominados pelos jovens de panelinhas, grupos estes que muitas vezes discriminam-se mutuamente, "demonstrando a importância da demarcação de um território, de afırmação de um 'estilo', ou, por que não, de uma identidade" (MANZANO, 2004, p. 24). Analisando alguns desses aspectos, Izabel Galvão e Marília Sposito (2004) explicam que tais jovens

cultivam amigos, mas distinguem a amizade da 'colegagem', esta mais freqüente [sic] e 
tratada como a capacidade de conversar muito sobre assuntos triviais e estabelecer boas relações. Estruturam grupos e tipos de conduta que os segmenta e permitem construir territórios de reconhecimento do outro, no mundo cotidiano das interações: os folgados, os stressados, os nerds, os populares. Nessa tipologia, as diferenças e as expectativas de conduta, atribuindo lógicas femininas e masculinas, aparecem: meninas populares são aquelas que "ficam" com muitos rapazes e recebem adjetivos pejorativos. São, também, aquelas mais fortes que poderão eventualmente proteger em casos de brigas aquelas mais frágeis e tímidas. (p. 372-373)

No conjunto das entrevistas, encontram-se, por exemplo, referências a jovens considerados muito inteligentes e estudiosos que despertam a antipatia dos colegas, o que provoca sofrimento para aqueles que são rotulados. Outros, ao contrário, não têm problemas de sociabilidade. Os que se destacam, os líderes, são conhecidos como os populares. A conquista de uma boa relação com os colegas é extremamente importante para esses jovens, que querem ser reconhecidos. Assim, eles encontram um espaço para dividir ideias, sonhos, problemas e alegrias, um espaço que geralmente não existe na convivência entre os jovens de seu bairro, já que os pais procuram proteger os filhos de possiveis más companhias. Quando indagados sobre o relacionamento com os colegas, eles frequentemente mencionam as experiências de preconceito que permeiam tais contatos. As dificuldades de convívio com os outros, bem como com as diferenças pessoais e culturais, são, em parte, consequência dos valores, das desigualdades e das injustiças de nossa sociedade, mas esses aspectos são atualizados e ganham suas próprias configurações no espaço escolar.

Portanto, as atividades de apropriação dos saberes escolares relacionam-se com esse processo. Identificam-se algumas atividades mais pertinentes do que outras quando se trata de enfrentar questões de preconceito, de dificuldade de relacionamento, de dificuldade para aceitar o diferente. Os modos de trabalho que privilegiam o diálogo entre os saberes escolares e os saberes desses jovens podem contribuir, por exemplo, para o estabelecimento de relações menos conflituosas no espaço escolar, ou ainda para problematizar e analisar essas dificuldades de sociabilidade por outros enfoques, a partir do trabalho mediado pelos saberes. Tal trabalho pode contribuir para a viabilização do distanciamento necessário e para um deslocamento de foco, possibilitando análises mais aprofundadas sobre essas questões, que, embora recorrentes e significativas na experiência escolar desses jovens, passam muitas vezes ao largo das práticas de apropriação dos saberes escolares.

\section{Desafios para a apropriação dos saberes escolares}

Os jovens pesquisados em nosso estudo depositam, nessa escola de ensino médio, uma grande expectativa em relação à possibilidade de encontrarem caminhos para um futuro melhor. Os dados indicam que eles não podem ser considerados os novos alunos do ensino médio no sentido apresentado por Dubet (1991). Segundo o autor, a experiência escolar dos alunos do ensino médio na França pode ser dividida entre: os verdadeiros lycéens, os bons lycéens, e os novos lycéens. Sobre os últimos, ele explica:

estes novos alunos são pessimistas [...] eles revelavam um pensamento mágico. Eles oscilam entre uma ausência de projetos de futuro e a formulação de projetos irrealistas. [...] Eles querem entrar na verdadeira vida, viajar, deixar o bairro [...] [Para eles] é suficiente querer as coisas para que elas aconteçam, [...] [Há um] sentimento de separação entre a escola e a vida. (p. 96-115)

Eles procuram construir seus projetos pessoais nos quais incluem os saberes escolares e valorizam a experiência na instituição esco- 
lar. No entanto, também é possível identificar indícios de que essa valorização da instituição escolar em suas vidas não significa, para uma parte desses jovens/alunos, uma relação satisfatória com a aprendizagem intelectual proposta pela instituição escolar. De acordo com os resultados dos questionários, respondidos por 2.093 alunos no âmbito da pesquisa-ação, os principais problemas enfrentados na escola são os problemas escolares (47\% das respostas), seguidos pelo problema das drogas (15\%), pelas agressões (14\%) e pela discriminação (6\%).

Os 221 textos (inventários de saber), produzidos pelos jovens/alunos do período diurno revelam que as aprendizagens mais valorizadas referem-se às relacionais e afetivas (aprendizagens de conformidade e de harmonia) ${ }^{5}$. Tais resultados aproximam-se dos obtidos em outras pesquisas que estudaram a relação com o saber de crianças e de jovens (CHARLOT, 1999; CENPEC; LITTERIS, 2001; LOMÔNACO, 2003).

Identificamos proximidades desses resultados com aqueles obtidos na pesquisa realizada por Charlot (1999) sobre a relação com o saber de jovens de meios populares do ensino médio profissional na França. Mesmo levando em consideração as diferenças entre o contexto educacional francês e o contexto brasileiro, bem como entre a especificidade das escolas de ensino médio profissional na França em relação à escola estudada, que proporciona uma formação geral aos alunos de ensino médio, as semelhanças entre os dados obtidos merecem uma análise.

Conforme afirma o autor, o universo de saber desses jovens (mais especificamente, seu universo de aprender) está centrado sobre aprendizagens relacionais e afetivas ou ligadas ao desenvolvimento pessoal, as quais totalizaram, em sua pesquisa, $48 \%$ dos resultados; em nosso estudo, identificamos uma porcentagem semelhante: 40,7\%. Em segundo

5- Apresentamos neste texto a análise dos inventários de saber dos jovens do período diurno, porque todos os outros procedimentos de pesquisa foram realizados com eles. Em um capítulo da tese de doutorado, esboçamos uma comparação entre os inventários de saber dos períodos diurno e noturno. lugar, na pesquisa de Charlot, são evocadas as aprendizagens intelectuais e escolares, as quais perfazem $24 \%$ do total; em nosso estudo, tais aprendizagens foram mencionadas por 27,3\% dos jovens. De acordo com Charlot, a ênfase dada a esse tipo de aprendizagem indica que esses jovens vivem em um mundo difícil, com relações tensas, sempre com risco de percalços, de conflitos e de perder a confiança neles próprios.

0 autor explica, ainda, que

a consciência desses jovens de meios populares está centrada sobre situações e nas relações com os outros, que elas permitem ou exigem e não sobre a construção de um eu reflexivo (je réflexif), muito reticente em e afırmar e mostrar uma constância identitária. (CHARLOT, 2009, p. 31)

\section{Portanto,}

'aprender' é, para eles, fundamentalmente, aprender a 'vida'. [...] $\mathrm{Na}$ escola, aprender significa ouvir o professor e memorizar o que ele explica [...]. Aprender através da vida, na vida, é fazer dela experiência, observá-la e refletir. (p. 264)

Tanto no estudo de Charlot (1999), como em nossa pesquisa, a família é o primeiro lugar de aprendizagem. Ela não é o deserto cultural, como muitos acreditam ser, pois os alunos valorizam também a educação recebida pelos pais, os conselhos sobre o que é certo ou errado. Outros aspectos recorrentes são o incentivo e a cobrança dos pais para que estudem, visando obter um futuro melhor, conforme os relatos que apresentamos a seguir:

Não tenho uma coisa específica, dizendo que eu aprendi isto e isto é o mais importante, mas, para mim, eu acho que as coisas mais importantes são aquelas que a escola da vida nos ensina, por exemplo:

6 - Esta obra é a tradução do livro de Charlot publicado em 1999. 
nunca abaixar a cabeça desistindo de lutar, porque aquilo que você quer, só porque perdeu uma vez; uma coisa que aprendi com meus pais é estudar muito, pois o estudo é uma das coisas que as pessoas não nos tomam e o que estaria sendo mais importante para mim no momento seria isto. (Renata)

Tanto no estudo de Charlot (1999) quanto em nossas análises dos inventários de saber, pode-se identificar que, para os jovens pesquisados, as atividades intelectuais relacionam-se com uma aposta no futuro. Nota-se que, para eles, as aprendizagens adquiridas na escola são de natureza variada e interpretadas como coisas que podem contribuir para alcançar, no futuro, um lugar melhor na sociedade. Pode-se identificar esse tipo de argumento no seguinte fragmento de relato:

0 mais importante para mim foi me conscientizar que, no ensino médio, eu estou praticando uma atividade que no futuro vai me garantir, mas também pensar que se eu não for bem aqui, que é uma escola forte, eu não vou bem na faculdade e muito menos no trabalho que possa fazer. [...] Quem sabe [...] um dia eu possa ser uma pessoa que tenha um futuro garantido nesse mundo onde um país de terceira não tem condições de permanecer firme. (Rodrigo)

Esse aluno apresenta uma contradição entre a perspectiva de um futuro melhor por meio dos estudos e as dificuldades cotidianas na apropriação dos saberes escolares, realizando tarefas que muitas vezes não são bem sucedidas. Em relação às dificuldades enfrentadas nessa nova experiência de escolarização, podemos também destacar outro depoimento retirado de um dos inventários de saber:

Este ano mudei de escola, porque onde eu estudava a escola era muito fraca e como eu nunca me contentei com pouco, me achei capaz de lutar por uma coisa que sabia que iria conseguir, mas, porém, não estava acostumada com o tipo da aula diferente, para quem não tirou nenhuma, sequer nota vermelha, já tinha tirado muitas. Talvez já seja o tempo de me atualizar, coisas que eu aprendia em um ano, aqui aprendo em seis meses. Se não conseguir ser melhor, talvez terei que mudar algumas coisas da minha rotina, mas se é para minha felicidade, eu consigo. É assim mesmo na vida a gente quebra a cara e quase sempre aprende [...]. Embora tudo seja difícil ainda acho um tempo para sorrir e esquecer de tudo aquilo que me faz chorar. (Regina)

Este e outros exemplos apresentam os questionamentos dos estudantes sobre os novos desafios apresentados na experiência de escolarização no ensino médio e uma tomada de consciência da distância entre suas expectativas iniciais e os resultados obtidos pelo veredicto escolar.

Não é possível considerar o sujeito da aprendizagem, o eu epistêmico, como imediatamente dado, "mas é preciso entendê-lo como uma certa postura de um sujeito envolvido tanto em relações de desejo como em relações sociais e institucionais" (CHARLOT, 2001, p. 20). 0 que mobiliza os sujeitos de nossa pesquisa é a ideia de que eles estão em uma escola para bons alunos e de que nela serão preparados para alcançar um futuro melhor. Tal ideia é veiculada pela família e reforçada pela boa imagem que a escola ainda apresenta à sociedade. No entanto, esses sujeitos, como eus empíricos (portadores de experiências que já buscaram interpretar), precisam construir-se como eus epistêmicos a partir das exigências intelectuais para as atividades escolares (CHARLOT, 2001).

Nesse processo, identifica-se que muitos dos estudantes enfrentam dificuldades para compreender tais atividades. Os resultados dos questionários, dos inventários de saber e, principalmente, das entrevistas revelam que os jovens pesquisados expressam um dis- 
curso de responsabilização sobre si próprios pelo sucesso ou fracasso nos estudos. Eles não compreendem por que, mesmo sendo considerados bons alunos por seus familiares e por si próprios, passam a ter um desempenho escolar abaixo do esperado.

A partir da análise das entrevistas, identificamos que determinados docentes, sem conhecer a relação desses estudantes com o saber, seus modos de pensamento, procuram simplesmente expor conceitos já sistematizados, os quais soam, para muitos jovens, como palavras jogadas ao vento. Podemos apresentar como exemplo disso a recorrência nos relatos dos jovens sobre a prática de alguns professores que se limitam a passar lição na lousa, explicar um assunto, sem estabelecer um diálogo entre esse assunto e as interpretações dos alunos em relação ao que estão aprendendo.

Estou ligado no professor, no que ele está falando, mas é comigo, entende, não entra [...] sinto tristeza, solidão, me sinto sozinho, o que estou fazendo aqui. (Carlos)

Parecetratar-se de dois mundos diferentes, como se esses jovens estivessem ouvindo uma língua estrangeira, não encontrando pontos de contato entre aquilo que já aprenderam e o que é ensinado. Os dados também revelam que não há indícios nos relatos dos jovens sobre uma preocupação dos docentes em ensinar alguns saberes específicos, tais como maneiras de estudar, de pesquisar, caminhos que possam ser percorridos para fazer os trabalhos etc.

Uma hipótese que levantamos é a de que os professores partem do pressuposto de que tais alunos já apreenderam determinado saber-fazer específico, necessário ao trabalho escolar. No entanto, pode-se afirmar que a maioria desses jovens não teve acesso a esses saberes em suas experiências anteriores.

Para esses alunos, estudar é assistir às aulas ou ler o que está escrito no caderno, e como eles não entendem as explicações ano- tadas no caderno das disciplinas nas quais têm dificuldade, desistem de estudar os conteúdos daquelas disciplinas. Podemos afirmar que 0 modo como eles compreendem a atividade de estudar, assim como determinadas práticas de professores, contribui para criar ou reforçar a ideia de que, para aprender, basta estar presente nas aulas, ouvir os professores. Daí a seguinte afirmação dos jovens: se ouviu o professor e não entendeu, não vale a pena insistir. Ademais, os jovens com mais dificuldades sentem vergonha de perguntar em sala de aula. Uma parte dos alunos investe no trabalho escolar somente quando gosta da disciplina ou quando gosta do professor. Caso contrário, tais alunos desistem de aprender o conteúdo de determinada disciplina, sobretudo quando se sentem incapazes de compreender o que foi ensinado. Percebe-se, no entanto, que essa desistência não é encarada com normalidade; ao contrário, representa sofrimentos que eles carregam no processo de escolarização. Identifica-se, ainda, que, para a maioria desses jovens com dificuldades, o prazer de estudar vincula-se à disciplina com a qual eles se identificam e às características pessoais de determinado professor.

No entanto, mesmo os jovens com dificuldades de estabelecer um vínculo com os saberes escolares apresentam, em seus argumentos, uma expectativa de que os professores contribuam para tal apropriação. Para isso, reivindicam explicações dos professores que os envolvam, que os situem no que é ensinado, que chamem a atenção dos alunos, que façam conexões entre a matéria e o dia a dia. Do nosso ponto de vista, essas reivindicações indicam que os alunos desejam encontrar pontos de diálogo entre seus saberes e aqueles veiculados pelo professor. Para aprender, é necessário realizar uma passagem, um trabalho de reorganização das aprendizagens como transformação de experiências, de estruturas de saberes e de ação em uma configuração biográfıca particular (DELORY-MOMBERGER, 2005).

Se os jovens levam para a escola modos de pensamento e de saberes construídos por analogias (BIARNĖS, 1999), por lógicas 
distintas daquelas privilegiadas pela escola, os professores que conseguem estabelecer diálogo entre os saberes escolares e os saberes dos jovens são citados como bons professores.

São recorrentes as afırmações dos alunos de que os professores valorizados são aqueles que explicam os conteúdos, que ensinam realmente. Portanto, os jovens distinguem o professor que tem um bom relacionamento com os alunos, mediado pelos saberes de sua área de conhecimento, daqueles que se omitem quanto ao seu papel de professor, partindo para uma relação de amizade pessoal. Identifica-se, ainda, que esses estudantes valorizam os professores que explicam com clareza, que sabem interpretar as dúvidas apresentadas pelos jovens. Pode-se afirmar que determinadas atividades propiciadas pela escola podem contribuir para reforçar o caráter instrumental da apropriação dos saberes e a representação dominante em nossa sociedade de que é possível adquirir saber naturalmente, sem um trabalho específico (GAUCHET, 2005). Por outro lado, quando apresentam exemplos de bons professores, os jovens referem-se a práticas docentes que, segundo pensam, contribuem para seu aprendizado:

A professora de Biologia é uma boa professora, ela vai buscar os detalhes, fala direitinho o que tem que fazer, fala tudo o que tem que fazer. Se alguém não entendeu, ela explica aquilo que o aluno quer saber. (Carlos)

Ele é admirado por todos porque sabe impor respeito, mas ele sabe ser amigo. Acho que para alguns professores falta isso, saber quando tem que ser amigo e quando tem que impor respeito. Não é questão de ser amigo pessoal. É questão de você respeitar a ideia do aluno. (Tânia)

Identificamos, ainda, que determinados jovens compreendem a especificidade do trabalho de apropriação dos saberes escolares e são menos vulneráveis às relações com os professores. Esses estudantes explicam que, para estudar, por exemplo, realizam pesquisas, buscam novas referências com os professores, fazem atividade em casa etc. Eles compreendem que não basta ouvir os professores; reconhecem que precisam realizar um trabalho de apropriação dos saberes. Do nosso ponto de vista, uma questão importante é que a escola de ensino médio não deve pressupor que os jovens já possuem tal relação com os saberes escolares. Trata-se de processos que precisam ser construídos. De acordo com Beatriz Lomônaco (2004), não basta respeitar o ritmo dos alunos, ou operar com o pressuposto de atividades agradáveis para garantir a construção de sentido.

As atividades significativas não são aquelas que se restringem ao repertório dos alunos. Dar sentido é atribuir significados, valores ao que se aprende, não porque o que se aprende tem uma aplicação imediata, mas pela mobilização que cria no indivíduo. (p. 22)

0 sentido surge na relação entre professor, aluno e objeto de saber (BIARNĖS, 1999), em um espaço intermediário criado por eles a partir de

uma prática entre e por alunos e professores: é nesse espaço intermediário construtivo, de uma prática de saber, que as experiências atualizam-se e ocorre a aprendizagem. (LOMÔNACO, 2004, p. 22)

Portanto, concordamos com Charlot (1999) quando ele afirma que

esse déficit de sentido por mais enraizado que esteja em uma relação com o mundo é também efeito das práticas da instituição e de seus agentes. (p. 33)

É importante salientar algumas atividades citadas como significativas por uma grande parte dos alunos pesquisados. Um exemplo é o projeto, desenvolvido pela professora de língua portuguesa, de aliar o ensino de literatura ao teatro. Tal projeto 
envolvia diferentes aspectos: leitura da obra literária, organização das peças, leitura das falas dos personagens, ensaios, apresentações, saídas para assistir a peças de teatro etc. 0 trabalho foi elogiado pelos alunos, sendo que cada um valorizou aspectos diferentes. Alguns comentaram sobre a transformação ocorrida em sua atividade de leitura: se, no início, liam os livros por obrigação, para realizar a tarefa da disciplina, posteriormente, como resultado da ação de ler, passaram a mudar o objetivo, ou seja, passaram a gostar de realizar a leitura. Outros referiram-se à possibilidade de trabalhar coletivamente; ao prazer de realizar um trabalho e apresentá-lo; aos conhecimentos que esse tipo de atividade proporcionou. Alguns, ainda, afirmaram que tal atividade contribuiu diretamente para a construção de seus projetos pessoais: uma jovem passou a desejar exercer artes cênicas como profissão, e outra incluía em seu projeto de vida organizar um grupo de teatro para apresentar peças nas escolas com o objetivo de discutir temas voltados à juventude, como gravidez, drogas etc.

Outro exemplo que podemos citar é um projeto da professora de arte no qual a docente procurou apreender dos jovens seus pontos de vista sobre violência - em geral e na escola - e apresentar um repertório sobre o tema para que eles pudessem, a partir da ampliação de seus referenciais, expressar suas ideias mediante o desenho e, ao mesmo tempo, aprender técnicas para desenhar. 0s jovens interpretaram de modo diverso a totalidade do trabalho: alguns compreenderam o objetivo da professora com o projeto e outros nem tanto, mas é importante identificar o modo como se envolveram na realização da atividade de desenhar e sentiram-se capazes para realizá-la.

Os dois exemplos elencados revelam propostas de atividades e modos de trabalho que apresentam indícios de diálogo entre os saberes pessoais dos alunos e os saberes escolares. Compreendemos tal diálogo como um processo que permite reconfigurar os saberes pessoais a partir de novas referências propiciadas pelos saberes escolares. Em outras palavras, a proposta de trabalho propicia o engajamento na atividade, por permitir que os jovens reconheçam, nos saberes veiculados, aspectos que se vinculam, de alguma forma, a suas questões pessoais e, ao mesmo tempo, por apresentar novos modelos, outras referências culturais que permitem um trabalho específico, no qual é possivel olhar para as questões pessoais a partir de outras perspectivas. Esse processo possibilita a passagem, a reconfiguração dos saberes pessoais e a transformação subjetiva do sujeito implicado em tal atividade.

\section{Considerações finais}

Segundo Rochex (1995),

as situações escolares, as atividades de aprendizagem e as interações que as envolvem [...] enraízam-se nos móbiles (motivos) de cada um dos seus protagonistas, nas suas trajetórias sociais, biográficas e nos aspectos de sua personalidade. (p. 48)

Quando os conteúdos produzidos no desenvolvimento dessas atividades de aprendizagem são pertinentes, eles têm uma eficácia social que não se reduz à realização pontual da própria atividade. Tais situações escolares produzem saberes transferíveis a outras situações, podendo gerar outros interesses e novos motivos que ultrapassam aqueles que originaram sua apropriação.

É fundamental compreender o alcance das atividades que a escola propicia aos jovens. No caso dos estudantes de nossa pesquisa, essa questão merece especial atenção. No conjunto dos dados, tanto do questionário sobre o clima escolar quanto nas entrevistas, identifica-se uma gradativa perda de adesão à escola, perda esta que culmina em muitas críticas e na desilusão perante a instituição no último ano. Se concordamos com Galvão e Sposito (2004) na questão de que a perda de adesão à escola está relacionada à visão instrumental dos 
alunos relativamente aos estudos, o que não possibilita um envolvimento com o trabalho de apropriação dos saberes escolares, nossa pesquisa também aponta para a responsabilidade das práticas educativas da escola em tal processo. Esses alunos são jovens cujas famílias, bem como eles próprios, possuem uma expectativa positiva quanto à escolarização no ensino médio. Identificamos que eles têm, potencialmente, uma relação positiva com a escola e com os estudos, o que contribui para o envolvimento nas atividades escolares, e que muitos deles apresentam dificuldades em relação aos modos de estudar, ao tipo de trabalho necessário para viabilizar a apropriação dos saberes. 0 reconhecimento desses aspectos é importante para se pensar qualquer projeto educativo relativo a esses jovens, qualquer proposta de atividade nas diferentes áreas do conhecimento.

É relevante ressaltar que nos chamou a atenção a angústia de boa parte dos estudantes em relação à falta de espaço para discutir aspectos relacionados a possíveis oportunidades de continuidade de estudos e de trabalho após o ensino médio. Apesar de considerarmos pertinente a preocupação de não transformar o ensino médio em uma mera preparação profissional para os jovens economicamente desfavorecidos, o que reforçaria a tão criticada dualidade que marca a história desse nível de ensino no país entre uma escola preparatória para as elites e outra de inserção no mercado profissional, não é justo que eles tenham menos informações e orientações do que outros, oriundos de famílias em melhores condições sociais e financeiras.
Para finalizar, retornamos à questão que nos levou a realizar este trabalho: a importância do saber pessoal para a aprendizagem dos saberes escolares. A fim de que os saberes escolares sejam alvo de um investimento do jovem, é necessário que eles tenham ressonância nas próprias questões que os sujeitos estão tentando compreender. Tal como afirma Christine Delory-Momberger (2005),

para serem apropriados, os saberes da escola devem passar por um trabalho de interpretação e de uma integração em sistemas de conhecimentos anteriores dos alunos (que não são idênticos entre eles, que são diferentes dos conhecimentos dos professores e não reproduzem o sistema objetivo e formalizado do domínio do saber no qual ele se integra). Todo objeto novo de aprendizagem pressupõe um processo único [...] de apropriação e de reconfiguração do conjunto dos sistemas adquiridos. (p. 89)

0 diálogo entre saberes escolares e não escolares não ocorre naturalmente. Há a necessidade de viabilizar encontros que permitam que os jovens entrem em um processo de apropriação e reconfiguração de seus saberes anteriores. A escola é, para eles, um espaço importante tanto para viverem suas juventudes, quanto para ampliarem seus saberes e referências culturais. Resta questionar se essa instituição e os agentes educativos que dela fazem parte estão conscientes da importante dimensão que exercem na vida desses jovens. 


\section{Referências}

ABRAMO, Helena W. Condição juvenil no Brasil contemporâneo. In: ABRAMO, Helena W.; BRANCO, Pedro P. (Orgs.). Retratos da juventude brasileira: análises de uma pesquisa nacional. São Paulo: Ed. Fundação Perseu Abramo; Instituto Cidadania, 2005. p. $37-72$.

BIARNÈS, Jean. Universalité, diversité e sujet dans l'espace pédagogique. Paris: L'Harmattan, 1999.

CENPEC; LITTERIS. 0 jovem, a escola e o saber: uma preocupação social no Brasil. In: CHARLOT, Bernard (Org.). Os jovens e 0 saber: perspectivas mundiais. Porto Alegre: Artmed Editora, 2001. p. 33-50.

CHARLOT, Bernard. Relação com o saber e com a escola entre estudantes de periferia. Cadernos de Pesquisa, São Paulo, n. 97, p. 47-63, maio 1996.

. Le rapport au savoir en milieu populaire: une recherche dans les lycées professionnels de banlieue. Paris: Anthropos, 1999.

(Org.). Os jovens e o saber: perspectivas mundiais. Porto Alegre: Artmed Editora, 2001. Artmed, 2005

Relação com o saber, formação dos professores e globalização: questões para a educação hoje. Porto Alegre:

A relação com o saber nos meios populares: uma investigação nos liceus profissionais de subúrbio. Porto: CHE/ Livpsic, Ciências da Informação, 2009.

CHARLOT, Bernard; BAUTIER, Elisabeth; ROCHEX, Jean-Yves. École et savoir dans les banlieues... et ailleurs. Paris: Armand Colin, 1992.

DAYRELL, Juarez. Juventude e escola. In: SPOSITO, Marilia (Org). Juventude e Escolarização (1980/1998). Brasília: MEC/Inep/Comped, 2002. p. 67-86.

DELORY-MOMBERGER, Christine. L'expérience biographique entre théorie et pratiques de formation. In: Histoire de vie et recherche biographique en éducation. Paris: Anthropos/Ed. Economica, 2005.

DUBET, François. Les lycéens. Paris: Seuil, 1991.

DUBET, François; MARTUCCELLI, Danilo. A l'école: sociologie de l'experience scolaire. Paris: Éditions Seuil, 1996.

FORQUIN, Jean-Claude. Escola e cultura: as bases sociais e epistemológicas do conhecimento escolar. Porto Alegre: Artes Médicas, 1993.

FREIRE, Paulo. Pedagogia do oprimido. Rio de Janeiro: Paz e Terra, 1987.

GALVÃO, Izabel; SPOSITO, Marília. A experiência e as percepções de jovens na vida escolar na encruzilhada das aprendizagens: a indisciplina, a violência e 0 conhecimento. Perspectiva, Florianópolis, v. 22, n. 2, p. 345-380, jul./dez. 2004.

GAUCHET, Marcel. Le sens des savoirs en question. Registro sonoro digital de conferência apresentada no dia 7 nov. 2005. Disponível em: <http://www.diffusion.ens.fr/index.php?res=conf\&idconf=935>. Acesso em: 14 jan. 2011.

LOMÔNACO, Beatriz. A relação com o saber de alunos da zona rural de um município da Serra da Mantiqueira. Relatório de pós-doutorado, supervisão de Leandro de Lajonquière. São Paulo: FEUSP, 2003.

Os sentidos, os saberes, os sabores: a construção do saber profissional do professor. 2004. 143p. Tese (Doutorado em Educação) - Universidade Paris VIII, Paris, 2004. (versão traduzida)

MANZANO, Cinthia Soares. A escuta ao aluno do ensino médio: ampliando o olhar sobre o jovem e o adolescente. 2004. 78p. Monografia (Trabalho de Conclusão de Curso em Educação) - Faculdade de Educação, Universidade de São Paulo, São Paulo, 2004. 
ROCHEX, Jean-Yves. Le sens de l'expérience scolaire: entre activité et subjectivité. Paris: Presses Universitaires de France, 1995.

SPOSITO, Marília. Uma perspectiva não escolar no estudo sociológico da escola. Revista USP, São Paulo, n. 57, p. 210-226, mar./ maio 2003.

VAN ZANTEN, Agnès. L'école de la périphérie: scolarité et ségrégation en banlieue. Paris: Presses Universitaires de France, 2001.

VIGOTSKI, Lev S. A formação social da mente: 0 desenvolvimento dos processos psicológicos superiores. São Paulo: Martins Fontes, 1998.

WOODS, Peter. La escuela por dentro: la etnografia en la investigación educativa. Madri: Ediciones Paidós, 1987.

Recebido em: 18.01.2011

Aprovado em: 10.05.2012

Rosemeire Reis é professora de graduação e pós-graduação na Universidade Federal de Alagoas (UFAL), doutora em Educacão pela Universidade de São Paulo (USP), sob orientação da Profa. Dra. Helena C. Chamlian, e pósdoutoranda pela Universidade Federal de Sergipe (UFS), sob supervisão do Prof. Dr. Bernard Charlot. Também é líder do grupo Juventudes, Culturas e Formação (UFAL) e integrante do grupo Profissão Docente: desafios contemporâneos (USP). 